\title{
Teaching Hybrid Courses across Disciplines: Effectively Combining Traditional Learning and e-Learning Pedagogies
}

\author{
Jonathan H. Westover and Jacque P. Westover
}

\begin{abstract}
This paper examines the role and effectiveness of hybrid course offerings within the higher education context. Providing a review of the growing body of academic literature on the effectiveness and learning outcomes of the hybrid model, this paper also provides a look at two distinct hybrid courses; one lower-division college algebra course and one upper-division human resource management course. The strengths and weaknesses of these hybrid courses are assessed and discussed alongside a brief proposal for continued academic research examining hybrid course best practices.
\end{abstract}

Index Terms-Hybrid courses, blended learning, online learning, math education, human resource management.

\section{INTRODUCTION}

With more and more pressure being put on institutions of higher education to provide both greater access to programs and reduce costs, more and more universities and colleges have been embracing the role of distance education progress and online courses. While the quality of online courses have continued to improve over the past decade, and while many students do quite well within the online learning environment opponents of online learning have long argued for the continued need for the face-to-face atmosphere and interactive environment that is important in the learning process for so many students. Within the context of this pedagogical and technology tension, the hybrid course (partially online, partially face-to-face) has been born.

First this paper will provide a brief introduction into the role of online learning in higher education, followed by a brief overview of the academic literature on hybrid course facilitation. The paper will then look at two short descriptive cases of hybrid teaching across disciplines, one from a lower-division college algebra course and one from an upper-division human resource management course. Strengths and weaknesses of these hybrid approaches will be discussed, followed by a look at the future research directions for hybrid teaching.

\section{ONLINE LEARNING}

There has been a tremendous amount of research in recent years that has examined online teaching and learning. Tallent-Runnels et al. [1] provided one of the most

Manuscript received July 11, 2013; revised September 12, 2013.

Jonathan $\mathrm{H}$. Westover and Jacque P. Westover are with Utah Valley University, Orem, Utah, USA (e-mail: jon.westover@gmail.com). comprehensive summaries of this body of knowledge, specifically examining course environment, learners' outcomes, learners' characteristics, and institutional and administrative factors. The authors conclude: That most of the studies reviewed were descriptive and exploratory, that most online students are nontraditional and Anglo American, and that few universities have written policies, guidelines, or technical support for faculty members or students. Asynchronous communication seemed to facilitate in-depth communication (but not more than in traditional classes), students liked to move at their own pace, learning outcomes appeared to be the same as in traditional courses, and students with prior training in computers were more satisfied with online courses. Continued research is needed to inform learner outcomes, learner characteristics, course environment, and institutional factors related to delivery system variables in order to test learning theories and teaching models inherent in course design.

\section{HYBRID COURSES}

Hybrid, or blended learning, courses are defined as "classes in which instruction takes place in a traditional classroom setting augmented by computer-based or online activities which can replace classroom seat time" [2]. As Jeffrey R. Young pointed [3], “... a growing number of colleges are experimenting with 'hybrid' or 'blended' models of teaching that replace some in-person meetings with virtual sessions". Scida and Saury [2] further argue that hybrid courses "... are becoming more and more the norm in higher education in the United States as earlier predictions of the explosion of completely online courses have not been borne out in practice" (see [4]-[7]). Furthermore, Young [3] argues that hybrid classes are less controversial among university faculty than offering traditional fully virtual courses and that "... hybrid courses may be a better way than fully online courses to help busy commuter students".

Many proponents of hybrid courses say their main motivation is to improve the educational experience for students and to relieve limited resource pressures on college campuses, pointing to research that demonstrates that using blended learning improves student success rates in learning outcomes and retention [8] and that hybrid courses alleviate campus classroom shortages and enrollment pressures [3]. Chuck Dziuban, director of the Research Initiative for Teaching Effectiveness at the University of Central Florida, says that his office's research shows that student success rates in hybrid courses on the Central Florida campus are 
"equivalent or slightly superior" to face-to-face courses, and that the hybrid courses have lower dropout rates than do fully online courses. Furthermore, Chris Dede, professor of learning technologies at Harvard University's Graduate School of Education, stated, "A strong case is beginning to be made on the basis of research evidence that many students learn better online than face-to-face, and therefore a mixture is the best way. What proportion that mixture should be would vary from course to course [3].

Over the past decade, there have been many advances in the technology and pedagogy of hybrid, or blended learning, courses. Moore [9] and Moore and Kearsley [10] have looked at the role of blended learning within the distance education landscape and Staker [11] has examined the role the disruptive innovation of online learning in the world of education. Additionally, Tucker [12] looked specifically at emerging technologies that are continuing to enhance student-centered classrooms and Bonk and Graham [13] have looked at the recent practices and trends in blended learning from a global perspective. More recently Adams [14] examined which blended learning strategy maximized learning outcomes and job impact and found that contextual factors are highly significant in looking at differences across four research groups. Additionally, Akyol and Garrison [15] and Akyol, Vaughan, and Garrison [16] emphasized the role of community building and development of a community of inquiry in order to increase effectiveness and success of online teaching and learning and Akyol and Garrison [17] found significant relationships among teaching presence, cognitive presence and social presence, and students' perceived learning and satisfaction in the course.

Finally, Aycock et al. [18] argue that "The power of the hybrid course model is its flexibility and its pedagogical effectiveness. Because it emphasizes active learning techniques, it increases student interaction with other students and the instructor." Additionally they concluded the following 10 key lessons on offering effective hybrid courses:

- Lesson \#1: There is no standard approach to a hybrid course.

- Lesson \#2: Redesigning a traditional course into a hybrid takes time.

- Lesson \#3: Start small and keep it simple.

- Lesson \#4: Redesign is the key to effective hybrid courses to integrate the face-to-face and online learning.

- Lesson \#5: Hybrid courses facilitate interaction among students, and between students and their instructor.

- Lesson \#6: Students don't grasp the hybrid concept readily.

- Lesson \#7: Time flexibility in hybrid courses is universally popular.

- Lesson \#8: Technology was not a significant obstacle.

- Lesson \#9: Developing a hybrid course is a collegial process.

- Lesson \#10: Both the instructors and the students liked the hybrid course model.

\section{BRIEF CASE 1: A COllege Algebra Hybrid Course}

Brief Course Overview: College Algebra is the general education course required by many majors at the university level. As such, students that are hoping to study in different disciplines often do not show great interest in mathematics and experience a great deal of math anxiety. A hybrid form of the course was developed (based on the following research: [12]-[14], [17]) in part, as a way for students to meet their requirement while helping to reduce their anxiety level.

E-Learning Class Components: In this particular College Algebra hybrid course, there are many online requirements to complement and supplement the in-class structure and face-to-face instruction. Before attending a class session on a particular set of mathematical concepts, students are expected to have already completed several online components. First, students are required to watch a video lecture of instruction, typically 20 minutes, covering that particular concept(s). Second, they have a set of practice problems, typically 5-6, that ideally cover each core concept or each possible variation of a given equation/problem that they would encounter in the future. Once this is complete, students are encouraged to begin their online homework assignment and complete as much as they are able and then come to class with questions prepared. Homework is not submitted until the day after the face-to-face class session, so students are able to complete the assignment after having asked questions and clarified any confusion they may have about the material.

Face-to-Face Class Sessions: In each face-to-face class session, the instructor provides an overview of the concepts covered and ensures that adequate time and attention is given to particular "trouble" aspects that present common stumbling blocks for students. The instructor then opens the class for questions. Ideally, students would have already completed all of their outside requirements and are prepared with any questions they needed to ask or things they needed clarified in order to feel confident to complete their assigned problem set. Once questions are answered and the instructor feels reasonably reassured that the students have overcome any major obstacles they may have encountered in their online assignments, the instructor would then facilitate an in-class activity to reinforce the student learning; often this activity takes the form of an open group "quiz" where students discuss and complete problems that would be similar to what they would find on a typical exam. The students work in groups and are encouraged to use their notes, textbooks, and any other resources they need in order to fully understand and complete the "quiz". Simultaneously, the instructor provides assistance with the quiz, moving from group to group and answering any questions or helping students through problems that they may find particularly difficult. After class, students are expected to complete their online homework assignment as well as be prepared for the next face-to-face class.

Technology Utilized: MyMathLab is the main online technology used in this hybrid course design. Students watch their online lectures through MyMathLab as well as complete and submit their homework assignments. MyMathLab is a great resource to use outside of class because of the many different approaches it uses to assist students to complete assignments. As the students work through their homework, each problem has links to various resources that students can turn to in order to get the immediate help that they need. For 
example, a given problem may have a link to a similar problem that shows step by step how to complete the problem, a video lecture that discusses the concept as well as a link to the section of the textbook that covers that concept, a link that will show them how to solve that exact problem as well as a new problem for them to complete in order to receive credit on their assignment. These helps, along with others, give students the resources they need in order to have a full understanding of a given concept.

\section{BRIEF CASE 2: AN INTRODUCTORY HR HybRID COURSE}

Brief Course Overview: Human resource management is a core required course for all major students across disciplines within the business school. As such, most students taking the course are not particularly interested in pursuing a career in the human resource field but are often seeking to simply fill a needed requirement. For years this class has been offered in traditional face-to-face sections, condensed weeknight sections, condensed weekend sections, and in online sections However, a couple of years ago a hybrid form of the course was also developed (based on the following research: [12]-[14], [17]) in an attempt to capitalize on the flexibility and cost-savings benefits of online courses, while also allowing for needed classroom interaction.

E-Learning Class Components: In this particular human resource management hybrid course, there are many online requirements to complement and supplement the in-class structure and face-to-face instruction. Before attending a class session on a particular set of human resource management concepts and principles, students are expected to have already completed several online components. First, students are required to watch a series of short online video lectures or instructional videos covering. Second, students are given a list of assigned readings that are followed by a related short case study write-up that they must do to demonstrate their understanding of the material and its application. Additionally, the students choose between three possible applicable current event articles and questions that relate to the assigned reading and require the students to exercise their critical thinking skills. The short application papers are submitted the course Canvas website each week and is accompanied by an online chat requirement to get them interacting with other students' responses the case and current event questions. All of this work occurs asynchronously prior to the face-to-face class session when the material is covered in greater depth. Following the face-to-face session, students are then required to submit a weekly learning reflection paper, where they further engage with the material through exploring their unique "ah-ha" learning moments and how the particular material applies specifically to them and their experiences (past and present).

Face-to-Face Class Sessions: In each face-to-face class session, the instructor focuses in on certain concepts and principles that need additional explanation and ensures that adequate time and attention is given to questions and confusing aspects of the readings and their learning application. In-class small-group and class discussions are utilized to provide opportunity for in-depth discussion of core issues (as the students have been required to already have done a substantial amount of class preparation related to the material). Short group activities and classroom learning simulations are also used as appropriate, with the aim of making each face-to-face session an opportunity for rich interaction and student engagement, while also providing clear, applicable, and actionable take-aways for each session. Finally, as mentioned above, after each class, students are expected to their weekly learning reflection paper on that week's material and then start the preparation process for the following week's face-to-face class session.

Technology Utilized: When this hybrid course was first developed, the online learning platform used was Blackboard. However, now the class uses a more instructor and student user-friendly interactive online learning platform called Canvas (which allows for all of the traditional online features of Blackboard, while also allowing for video chats between students and with instructors, dynamic online discussions, connectivity to social media and networking sites, and many other useful online features). Students in this specific hybrid course mostly utilize the online discussion boards, assignment submissions, and file management aspects of Canvas to facilitate their out-of-class asynchronous learning.

\section{STRENGTHS AND WEAKNESSES OF THE HYBRID METHOD}

Strengths and Weaknesses of a College Algebra Hybrid Course: Based on the 10 key lessons on offering effective hybrid courses offered by Aycock et al. [18], also supported by more recent research findings (see: [12]-[14], [17]), we found that there were several weaknesses to this model of hybrid course for teaching college algebra. First and foremost, this model was assignment intensive. Each student was required to watch the video lecture, complete practice problems, do a homework assignment, as well as a quiz for each section. We felt that this was a significant requirement load for this class, although there are many instructors that feel that this was certainly appropriate for the given credit load. Secondly, we found that students were not always prepared for the in-class instruction with their questions or things that they wished to discuss in order to make the most of their in-class time with the instructor. We believe that this was due to multiple factors, including students not starting homework before class, not wishing to appear unknowledgeable on a certain topic, and the early hour at which this particular class was taught $(7 \mathrm{am})$. A strength of this approach was the multiple learning approaches that students were required to take when learning a new concept. This allowed for multiple pedagogical techniques to be used by each student in order for them to have a better understanding of each concept.

Strengths and Weaknesses of an Introductory HR Hybrid Course: As with the college algebra hybrid course, based on the 10 key lessons on offering effective hybrid courses offered by Aycock et al. [18], also supported by more recent research findings (see: [12]-[14], [17]), we found that the effectiveness and quality of each weeks' face-to-face sessions was largely dependent on each students' personal preparation, with some students obviously consistently taking the lead in the in-class discussions and activities while other students continue to be more passive (with even a bit of 
a free rider effect happening at times; as with the college algebra course, the human resource management hybrid course is also very assignment intensive). A clear strength of this approach is the multiple learning approaches and the requirement for continual reflection, application, and deep learning of the material, rather than focusing on surface-level and more superficial aspects of the content.

\section{Proposed Future Research on Hybrid Courses}

Future research needs to continue to explore the effective use of hybrid courses within the ever-changing landscape of higher education. Such research needs to look in-depth at learning and various stakeholder outcomes of hybrid teaching, as compared directly to a variety of other teaching models (including traditional semester long face-to-face courses, condensed face-to-face courses, strictly online courses, etc.) across academic disciplines. Much of this research can and may take a comparative case-methodology approach, but where feasible, other rigorous quantitative, qualitative, and mixed-methods approaches should also be utilized.

\section{CONCLUSION}

In conclusion, it is important to both recognize and embrace that the landscape of higher education is continuing to change. With the continued increase in online and distance education course offerings, including the growing popularity of "MOOCs" (massive open online courses), institutions of higher education need to find more cost-effective and value added ways to provide reasonably priced, meaningful and substantial education for its students. The adoption of hybrid courses provides a unique opportunity to bridge the divide but much more research needs to be conducted to demonstrate the utility and sustainability of such an approach. The brief comparative cases provided herein demonstrate that there are indeed both strengths and weaknesses to the hybrid approach and that a one-size-fits-all model will likely not be effective when it is applied to a diverse set of students, across a diverse set of disciplines.

\section{REFERENCES}

[1] M. K. Tallent-Runnels et al., "Teaching courses online: A review of the research," Review of Educational Research, vol. 76, no. 1, pp. 93-135, 2006.

[2] E. E. Scida and R. E. Saury, "Hybrid courses and their impact on student and classroom performance: A case study at the University of Virginia," CALICO Journal, vol. 23, no. 3, pp. 517-531, 2006.

[3] J. R. Young, "Hybrid' Teaching Seeks To End the Divide between Traditional and Online Instruction," Chronicle Of Higher Education, vol. 48, no. 28, pp. A33-A34, 2002.

[4] M. T. Ijab, R. Anwar, and S. Hamid, "Teaching and learning of e-commerce courses via hybrid elearning model in Unitar," Journal of Electronic Commerce in Organizations, vol. 2, no. 2, pp. 79-94, 2004.

[5] E. B. Lindsay, "The best of both worlds: Teaching a hybrid course," Academic Exchange Quarterly, vol. 8, no. 4, pp. 16-20, 2004.

[6] D. Sauers and R. C. Walker, "A comparison of traditional and technology-assisted instructional methods in the business communications classroom," Business Communication Quarterly, vol. 67, no. 4, pp. 430-442, 2004.

[7] H. G. Willet, "Not one or the other but both: Hybrid course delivery using WebCT," The Electronic Library, vol. 20, no. 5, pp. 413-419, 2002 .

[8] T. Boyle, C. Bradley, P. Chalk, Jones, and P. Pickard, "Using blended learning to improve student success rates in learning to program," Journal of Educational Media, vol. 28, no. 2-3, pp. 165-178, 2003.

[9] M. G. Moore, Handbook of distance education, Routledge, 2013.

[10] M. G. Moore and G. Kearsley, Distance education: A systems view of online learning, CengageBrain.com, 2011.

[11] H. Staker, "The Rise of K-12 Blended Learning: Profiles of Emerging Models," Innosight Institute, 2011.

[12] C. R. Tucker, Blended Learning in Grades 4-12: Leveraging the Power of Technology to Create Student-Centered Classrooms, SAGE, 2012.

[13] C. J. Bonk and C. R. Graham, The handbook of blended learning: Global perspectives, local designs, Wiley. Com, 2012.

[14] J. Adams, "Blended Learning: Instructional Design Strategies for Maximizing Impact," International Journal on E-Learning, vol. 12, no. 1, pp. 23-44, 2013.

[15] Z. Akyol and D. R. Garrison, "Community of inquiry in adult online learning: Collaborative-constructivist approaches,” in T. T. Kidd (Ed.), Adult learning in the digital age: Perspectives on online technologies and outcomes (Ch.VI), Hershey, PA: IGI Global, 2009.

[16] Z. Akyol, N. Vaughan, and D. R. Garrison, "The impact of course duration on the development of a community of inquiry," Interactive Learning Environments, 2011

[17] Z. Akyol and D. R. Garrison, "The development of a community of inquiry over time in an online course: Understanding the progression and integration of social, cognitive and teaching presence," Journal of Asynchronous Learning Networks, vol. 12, no. 2-3, pp. 3-23, 2008.

[18] A. Aycokc, C. Garnham, and R. Kaleta. (2002). Lessons learned from the Hybrid Course Project. Teaching with Technology Today, [Online]. Available: www.uwsa.edu/ttt/articles/garnham2.htm

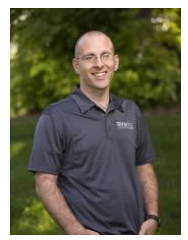

Jonathan H. Westover, who is a Ph.D. is an assistan professor of Business at Utah Valley University, specializing in strategic international human resource management and organizational behavior. $\mathrm{He}$ is also a human resource development and performance management consultant. He received his Doctorate of Philosophy and Master of Science degrees in the Sociology of Work and Organizations and Comparative International Sociology from the University of Utah. Additionally, he received his Master of Public Administration degree (emphasis in human resource management) from the Marriott School of Management at Brigham Young University. His ongoing research examines issues of globalization, labor transformation, work-quality characteristics, and the determinants of job satisfaction cross-nationally.

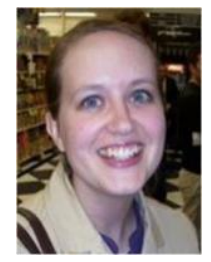

Jacque P. Westover is a part-time professor of Mathematics and Developmental Math in the College of Science and Health and University College at UVU. She received her B.A. in Math Education form Brigham Young University and her M.A. in Math Education from Western Governors University. Her teaching interests include Calculus, Statistics and Probability, Induction and Recursion, Modeling, Number Systems, Euclidean and Non-Euclidean Geometry, and Linear Algebra, Ordinary Differential Equations, Survey of Geometry, Theory of Analysis, Abstract Algebra. A published author and experienced presenter at academic conferences around the world, her research interests include Math Teaching in Public Schools, Teaching with Technology, Theory and Methods of Education, Multicultural and Exceptional Education.

Professor Westover was recently a Fulbright Scholar to Minsk, Belarus. He taught in the MBA program in the School of Business and Management of Technology at Belarusian State University and conducted research and consulted with business and civic groups on human resource development and performance management. 